\title{
The Mysterious Hypnotic Analgesia: Experimental Evidences
}

\author{
Edoardo Casigliaa, ${ }^{1,2}$ Valérie Tikhonoff ${ }^{1,3}$, Federica Albertini ${ }^{1,3}$, Antonio M. Lapenta1, \\ Federica Gasparotti1,3, Francesco Finatti ${ }^{1}$, Augusto M. Rossi' ${ }^{1}$, Gastone Zanette ${ }^{1,4}$, \\ Margherita Giacomello1, Nunzia Giordano', Jacopo Favaro', ${ }^{1,5}$ Enrico Facco, ${ }^{1,2}$

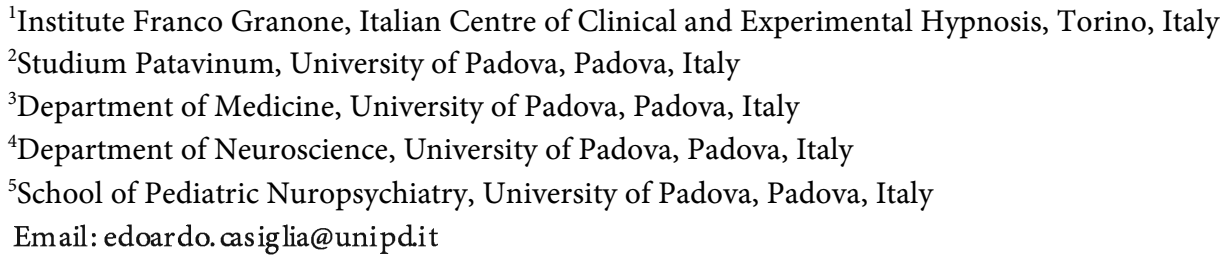

How to cite this paper: Casiglia, E., Tikhonoff, V., Albertini, F., Lapenta, A. M., Gasparotti, F., Finatti, F., Rossi, A. M., Zanette, G., Giacomello, M., Giordano, N., Favaro, J., \& Facco, E. (2018). The Mysterious Hypnotic Analgesia: Experimental Evidences. Psychology, 9, 1935-1956. https://doi.org/10.4236/psych.2018.98112

Received: June 11, 2018

Accepted: July 31, 2018

Published: August 3, 2018

Copyright (C) 2018 by authors and Scientific Research Publishing Inc. This work is licensed under the Creative Commons Attribution International License (CC BY 4.0). http://creativecommons.org/licenses/by/4.0/

\begin{abstract}
In the last years, the Laboratory of Experimental Hypnosis of the University of Padova and of the Institute Franco Granone of Torino, also in collaboration with the Foundation Hospital San Camillo in Venice, studied the effectiveness and the mechanisms of hypnotic analgesia in non-trigeminal an trigeminal pain. In this paper, the results of our work are summarized, starting from what was already known on the topic and exploring experimentally many different aspects of hypnotic analgesia. All the studies described in the present paper were conducted following scientific protocols and using the methods and means of Galilean science, employing in particular many instruments pertaining to human physiology and belonging to cardiology and neurology. This leads to the demonstration that hypnotic analgesia is an objective, real and measurable phenomenon.
\end{abstract}

\section{Keywords}

Hypnosis, Analgesia, Anaesthesia, Pain, Pain Control, Experimental Setting, Physiology, Cold Pressor Test, Ischemic Pain, Dentistry, Surgery, Reflex Response, Sympathetic Drive, Electroencephalography

\section{The Real and Concrete Nature of Hypnosis}

In the last 25 years, the Laboratory of Experimental Hypnosis afferent to the University of Padova and to the Institute Franco Granone Italian Centre of Clinical and Experimental Hypnosis of Torino, Italy, demonstrated that sugges- 
tions given in hypnotic trance are able to induce behavioral, cognitive and physical modifications that can be studied and measured. In experimental setting, electroencephalographic changes (Casiglia et al., 2010; Casiglia, Tikhonoff, Giordano, Regaldo, Facco et al., 2012; Priftis et al., 2011), hallucinations (Casiglia et al., 1997, 2006), lateral neglect (Priftis et al., 2011), age regression (Giordano, Tikhonoff, Tosello, Lapenta, \& Casiglia, 2012), alexia (Casiglia et al., 2010), amusia for rhythm (Facco, Ermani et al., 2014), muscular paralysis (Casiglia \& Mentesana, 2018), modification of vascular diameter and flow at peripheral and central level (Casiglia et al., 2007, 2016; Tikhonoff, Senzolo, Lapenta, Palatini, \& Casiglia, 2018), increase of physical and psychic performance (Tikhonoff et al., 2012), and analgesia (Casiglia et al., 2007, 2015, 2016; Facco et al., 2009, 2013; Facco, Casiglia, Masiero et al., 2011; Facco, Casiglia, Zanette et al., 2011; Facco, Casiglia, Zanette, \& Testoni, 2018; Facco, Zanette, \& Casiglia, 2014) were easily produced by our research group and quantified with the methods and the tools that are peculiar of human physiology (Casiglia, Tikhonoff, Giordano, Regaldo, Facco et al., 2012; Casiglia, Tikhonoff, Giordano, Regaldo, Tosello et al., 2012).

The effects of hypnosis are therefore real, not only subjective (Casiglia, 2008) but also objective, and take place not only in psychic but also in physical context.

Since 2004, our Laboratory has considered hypnosis as a tool for evaluating cortical activity in experimental setting (Casiglia et al., 1994).

\section{How to Organize an Experiment Concerning Hypnosis}

Experimental hypnosis is very different from hypnosis performed in other settings, for instance in psychotherapy. Apart from the need of preventive approval by an Ethics Committee and of the participants' informed consent, experimental hypnotism requires a large and trained research staff (a "critical mass"), availability of technological devices, and a conspicuous number of compliant highly hypnotizable participants (highs). The methodology of experimental hypnotism (Figure 1) has been widely described by our research group (Casiglia et al., 1997, 2007, 2010, 2015, 2016; Casiglia, Albertini et al., 2018; Casiglia, Finatti, Gasparotti et al., 2018, Casiglia, Finatti, Tikhonoff et al., 2018; Casiglia, Tikhonoff, Giordano, Regaldo, Facco et al., 2012; Casiglia, Tikhonoff, Giordano, Regaldo, Tosello et al., 2012; Facco, Casiglia, Masiero et al., 2011; Facco, Casiglia, Zanette et al., 2011; Facco et al., 2018; Facco, Zanette et al., 2014; Giordano et al., 2012; Priftis et al., 2011; Tikhonoff et al., 2018), and will not be repeated here in details. In brief, in our Laboratory, hypnotizability is previously ascertained through the Italian version of the Harvard Group Scale of Hypnotic Susceptibility (De Pascalis, Russo, \& Marrucci, 2000; Younger, 2005) or the Hypnotic Induction Profile (Facco et al., 2017). Each subject undergoes a preliminary session in order to establish a valid interpersonal rapport between the operator and the participant. Subjects are guided through verbal suggestions to focus on a single idea, excluding any other internal or external stimuli. Signals such as the closing of the eyes, the relaxation of facial muscles, the lower jaw dropping and the 


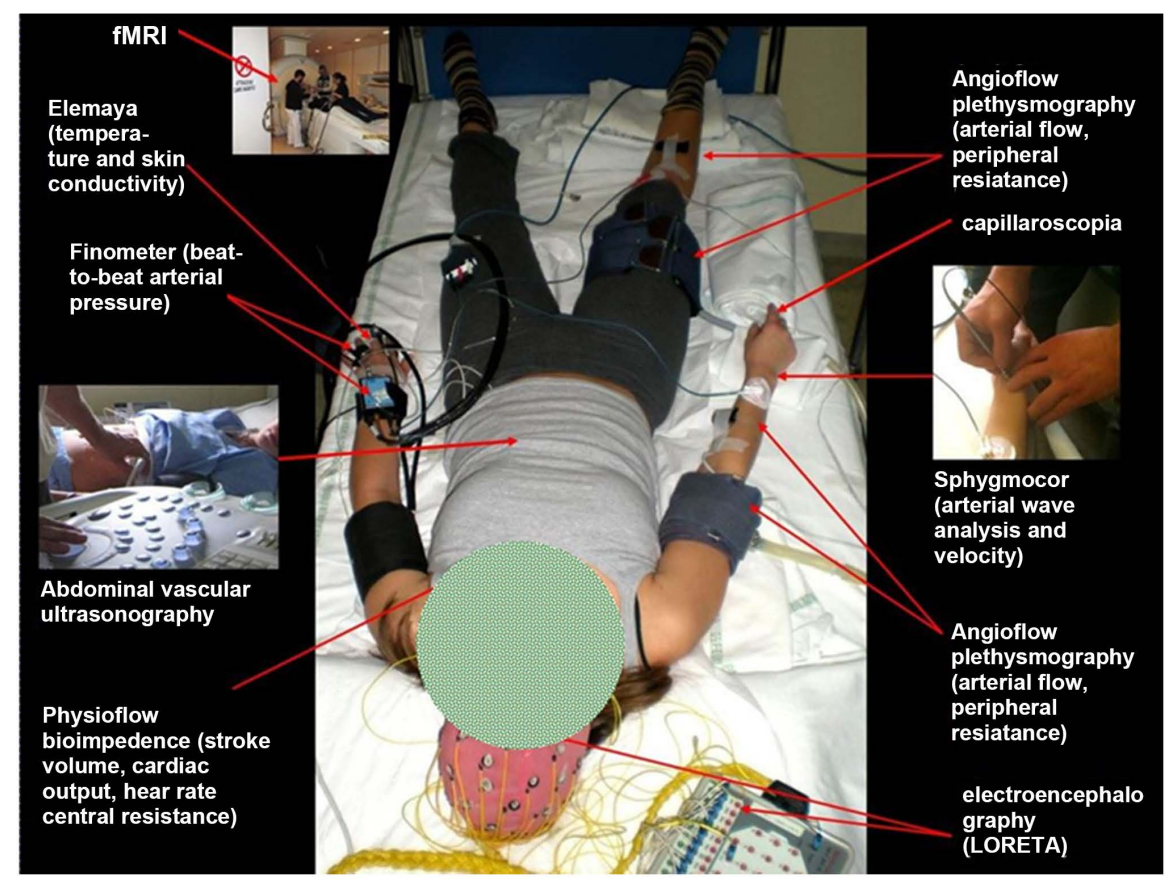

Figure 1. General setting for the Experiments jointly organized in the Laboratory of Experimental Hypnosis at the University of Padova, at the Institute Franco Granone in Turin and in the Hospital San Camillo in Venice (Italy); fMRI: functional magnetic resonance; LORETA: low-resolution brain electromagnetic tomography.

slower breathing (Casiglia, 2015) allow the hypnotist to verify the hypnotic state and to maintain it with appropriate suggestions.

Even when no post-hypnotic conditioning of induction is left, this procedure allows reaching a faster and more effective plastic monoideism during the experimental session.

\section{Hypnotic Analgesia in Acute Pain}

\subsection{Hypnotic Analgesia Obtained by Direct Suggestion of Analgesia}

Does hypnotic analgesia exist? It is really easy to obtain analgesia in hypnotic setting, particularly in highs, although the chain of events remains uncertain. When we performed the first studies on this topic, a convincing theoretic basis about the mechanisms of hypnotic analgesia was lacking, and hypnotic analgesia remained a mysterious phenomenon whose mechanism and explanation were quite unknown. The fundamental question on whether hypnotic analgesia was due to mere subjective dissociation (with an Ego perceiving pain and another Ego saying pain is not present), or to a real and measurable block of pain transmission, had never be unanswered.

Hypnotic analgesia is often administered in the form of the so-called hypnotic focused analgesia (HFA) (Sharav \& Tal, 2006), i.e. limited to a body segment. HFA, having the meaning and the effect of pharmacological local anaesthesia, 
has been used without problems in minor surgery, in dentistry and in troublesome maneuvers. To our knowledge, when we started our studies, the mechanisms of HFA were not fully explored in experimental setting and its physiological bases were largely unknown. Hypnotic anaesthesia had never been described. Not only this, but no stratification into HFA in trigeminal and non-trigeminal pain had been performed. Simply, it was patently evident and clear that HFA existed and worked for suffering patients. HFA was therefore confined to the subjective level.

Since 2004, in experimental and controlled clinical setting (Casiglia et al., 2007, 2015, 2016; Facco et al., 2009, 2013, 2018; Facco, Casiglia, Masiero et al., 2011; Facco, Casiglia, Zanette et al., 2011; Facco, Zanette et al., 2014), we repeatedly demonstrated that subjective perception of pain is reduced-even abolished-in highs ${ }^{1}$ experiencing HFA. As, for the participant to an experiment, pain is the marker of itself, the effectiveness of HFA is demonstrated by subjective pain reduction, but we demonstrated HFA was real at an objective level too. This topic is going to be explained hereafter.

Ways to elicit experimental pain. The way to produce pain in experimental setting must 1) be innocuous for the participant, 2) be accepted by the participant, and 3) be accepted by ethics committee.

Two effective pain-makers are the cold pressor test (CPT) (Casiglia et al., 2007; Casiglia, Tikhonoff, Giordano, Regaldo, Facco et al., 2012; Mitchell, MacDonald, \& Brodie, 2004; Peckerman et al., 1998; Sevre \& Rostrup, 1999) and the administration of electrical stimuli (Casiglia et al., 1997). The former consists in keeping a hand in icy water at $0^{\circ} \mathrm{C}$ temperature, inducing a very intense ischaemic pain, which is usually tolerated for 1 - 2 minutes (Casiglia et al., 2007; Freeman, Barabasz, Barabasz, \& Warner, 2000; Peckerman et al., 1991, 1994; Sevre \& Rostrup, 1999). This test, when applied to subjects free to interrupt the procedure in every moment, presents three advantages: 1) it can be standardized, 2) its duration reflects pain tolerance, and 3) its hemodynamic consequences can easily be measured, thus providing another demonstration of the reduction or resolution of the painful stimulus. The CPT is well known by cardiologists, who employ it as a provocative test to diagnose coronary artery disease (in fact, the CPT increases not only arterial resistance in all body districts including the coronary one, but also heart work load). Electrical pain can be obtained using electric stimulation of median nerve (ESMN) by a device giving square-wave direct current electric discharges at increasing intensity and at a frequency of 2 stimuli.s ${ }^{-1}$. This pain has the characteristic to disappear immediately after the participant presses a button so turning the device off (Casiglia et al., 1997).

\footnotetext{
${ }^{1}$ We always chose highs as participants in experimental setting because previous studies have shown that they tend to show stronger experiences of hypnotic pain inhibition (Horton, Crawford, Harrington, \& Dawns, 2004); since our aim is not to demonstrate that hypnotic analgesia can be applied to everybody but to characterize its potentiality, it is better to have highs (if we decide to study the maximal effects of jumps, it is convenient to choose highly performing athletes).
} 


\subsection{How to Demonstrate and Measure Pain and Its Inhibition in Experimental Setting}

Unfortunately, there is no mean to measure pain directly. Deciding if a participant is suffering pain, and possibly measuring its intensity, is a very difficult task.

A possible way is to measure the cardiovascular consequences of pain, for instance the reflex variations of the sympathetic drive, reflected by variations of peripheral resistance (PR). As these modifications-always present in the absence of analgesia-are proportional to pain, the researcher can not only ascertain if pain is really present of absent, but also have an indirect measure of its variation, for instance if hypnotic analgesia really reduces it and of which extent. This method pertains to hypnotists expert in cardiology (Casiglia et al., 1997).

Another way to ascertain if a participant is experiencing pain is functional magnetic resonance imaging (fMRI), that gives information about the brain areas that are active in a given moment or phase. Brodmann areas 1, 2 and 3 (primary sensitive areas) are the natural target of this research: they are active if pain is present and partially or totally silent if pain is reduced or blocked (for instance, if hypnotic analgesia works). This method pertains to neurologists expert in fMRI (McGeown, Mazzoni, Venneri \& Kirsch, 2009; McGeown, Mazzoni, Vannucci, \& Venneri, 2015).

\subsection{Is Hypnotic Analgesia a Merely Subjective Phenomenon?}

Dimension of the problem. For many years, it has been impossible to answer this question. When we started our research, evidences of hypnotic analgesia were practically limited to subjective visual analogue scales. The basic question is: is hypnotic analgesia an objective, repeatable and measurable phenomenon rather than a mere subjective neglect? In other words, is hypnotic analgesia nothing more than an inhibitory hallucination accompanying dissociation or is "due to a genuine block of pain"? (Casiglia et al., 2007). At first, we studied hypnotic analgesia as HFA.

Cardiovascular approach: non-trigeminal pain (NTP). Due to the cardiological orientation of our staff and to our expertise in the field, our first idea was to employ cardiovascular models to answer the question above. The general model of this series of experiments, concerning non-trigeminal pain, produced a series of co-coordinated papers. After informed consent, we decided to induce highs in hypnosis, to give them a direct suggestion of analgesia, and to test their reaction to NTP. As cardiologists, we knew NTP is always accompanied by a sympathetic reflex reaction represented by an increase of PR due to vasoconstriction and to reduction of cardiac output in response to painful stimuli (Casiglia, Tikhonoff, Giordano, Regaldo, Facco et al., 2012; Casiglia, Tikhonoff, Giordano, Regaldo, Tosello et al., 2012; Ibrahim, 1975). As a general rule, in our laboratory participants underwent "pain" and "pain + HFA" in intra-subject latin-square protocols (random sequence) where each participant was the con- 
trol of him/herself. Cardiac output (in $1 \cdot \mathrm{min}^{-1}$ ) and arterial blood pressure (in $\mathrm{mmHg}$ ) were continuously measured in both conditions, and PR (in units of resistance $=\mathrm{mmHg} \cdot \mathrm{min} \cdot \mathrm{ml}^{-1}$ ) were calculated.

The question was if the PR increase due to pain would be reduced during HFA: if so, HFA had to be considered physical, real and objective, as the reflex leading to PR response to pain does not involve consciousness, has no cognitive meaning, is not under voluntary control and is completely unconscious (Ibrahim, 1975). The results demonstrated a significantly lower PR increase following HFA in comparison to non-hypnotic conditions (Figure 2, left panel). Furthermore, in our experiments pain tolerance was also objectively increased by hypnotic analgesia, as the time of voluntary painful permanence in icy water and the intensity of current voluntarily tolerated in ESMN were significantly greater (Casiglia, Tikhonoff, Giordano, Regaldo, Facco et al., 2012; Casiglia, Tikhonoff, Giordano, Regaldo, Tosello et al., 2012; Ibrahim, 1975). Increase of pain tolerance is another objective demonstration of the effects of hypnotic analgesia.

Cardiovascular approach: trigeminal pain (TP). When we started our research on hypnotic analgesia in TP, the undemonstrated general belief was that the behavior of PR accompanying TP was different from that accompanying NTP. In particular, there was the suspect that TP (deriving from mouth, maxillofacial complex, nose and paranasal sinuses) induced a decrease-rather than an increase-in PR. TP is of particular interest for dentists and otolaryngologists, who are used to observe syncopes during painful maneuvers in those body

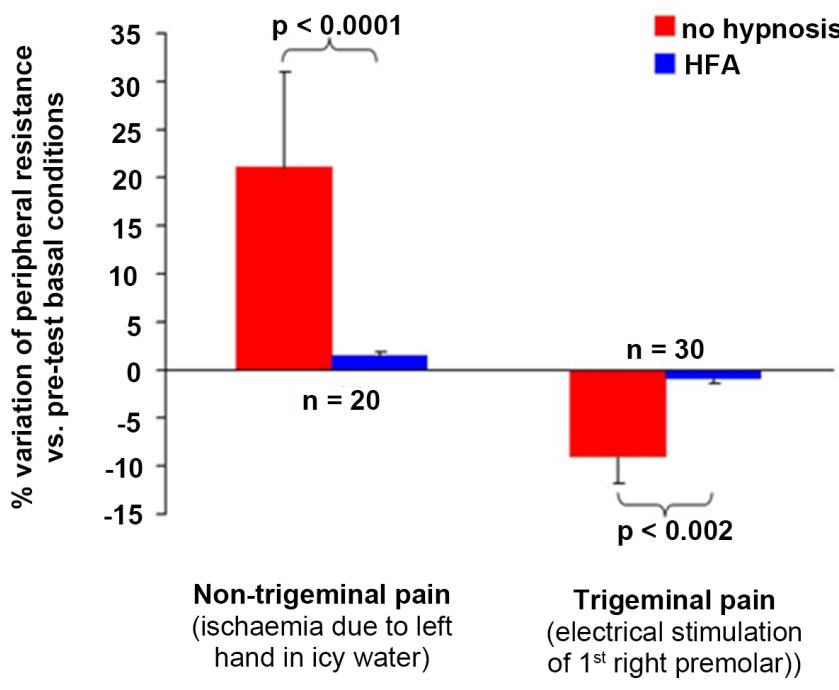

Figure 2. Percent variation from baseline of peripheral resistance (PR) during non-trigeminal pain (NTP) and trigeminal pain (TP). Both pains were tested out of hypnosis and in hypnotic focused analgesia. In this latter condition, both the expected physiological reflex PR increase in response to NTP and the expected physiological reflex $\mathrm{PR}$ decrease in response to $\mathrm{TP}$ were significantly and strongly reduced. This demonstrates that painful stimuli are really blocked and not only dissociated, supporting the gate control theory for both types of pain. 
areas. Our idea was that these syncopes (often erroneously attributed to chemical local anaesthetics) were due to a PR fall secondary to TP. We therefore preliminarily provided (to our knowledge, for the first time) the demonstration that PR actually decreased during TP: in an experimental model, we proved that, during TP, PR tended to fall rather than to increase (Facco et al., 2009; Facco, Casiglia, Masiero et al., 2011). We then proceeded with another similar experiment, but in this case the aim was to ascertain whether or not HFA applied to facial complex (for instance, to dental pulp) was able to reduce the expected reflex PR fall following TP. As shown in Figure 2 (right panel), this fall was significantly reduced by when HFA was suggested, so confirming the validity of the model. Pain tolerance was also increased.

Lessons from the cardiovascular approach. The combination of the modifications observed in NTP (inhibition of the expected reflex PR increase) (Casiglia et al., 2007, 2015, 2016) and in TP (inhibition of the expected PR fall) (Facco et al., 2013; Facco, Casiglia, Zanette et al., 2011) confirmed our hypothesis that hypnotic analgesia was a real, objective and measurable phenomenon. Otherwise, the reflex response to pain would be maintained. This cleaned up the theories stating hypnotic analgesia was based on dissociation, often preferred by psychologists. In fact, if the neodissociation theory (a classic "state theory") or the so-called theory of the neuromatrix were the explanation of hypnotic analgesia, pain-independent of its localization - would be accompanied by unmodified PR (Ibrahim, 1975). Furthermore, both "PR increase" in NTP and "PR decrease" in TP-although of opposite sign-were inhibited, demonstrating that pain was really blocked by hypnotic analgesia at a certain level of the nervous system. In fact, the participants were unaware of the PR variations during pain, and even more so of the differences in PR behavior due to the two types of pain, so that no cognitive explanation could justify the variations of cardiovascular effects of hypnotic analgesia. How can hypnotic analgesia lead to a block of the cardiovascular consequences of peripheral pain? It is likely that top-down fibers, originating in the pre-genual cingulate, dorso-lateral pre-frontal, anterior insular and anterior cingulate cortex, as well as in the hypothalamus and the amigdala, can inhibit nociceptive conduction in the spinal cord (Melzack \& Wall, 1965; Ossipov, Dussor, \& Porreca, 2010). Being cortical in origin, these fibers can easily respond to hypnotic suggestions no less than to the usual thought, but this latter, outside the context of hypnosis (for instance in distraction techniques), is less effective.

Neurological approach: role of imaging. If hypnotic analgesia really blocks painful stimuli, neuroimaging should demonstrate it. The focus of this hypothesis is on the primary sensitive areas ( $\mathrm{S} 1, \mathrm{~S} 2$ and $\mathrm{S} 3$, also called the Brodmann areas 1, 2 and 3). In the presence of pain, these areas are active, while in the absence of painful stimuli or in the presence of an effective analgesia they must be inactive. fMRI is the gold standard for this type of experiments. As no magnetic object can enter the fMRI tunnel, CPT (requiring ice only) is the best way to produce pain in this setting. In a set of more recent experiments, we asked highs 
to undergo fMRI both without any hypnotic suggestion and during HFA, in a random sequence. In both conditions, they had to undergo a CPT producing ischaemic pain, putting their left hand in a plastic container while their brain was scanned. The methods used in the analysis of fMRI signals go beyond the aims of the present paper. It is sufficient to say that the areas S1, S2 and S3 in the post-central gyrus were activated in right hemisphere during pain, and silent in HFA (Casiglia, Finatti, Gasparotti et al., 2018).

Lessons from the neurological approach. These findings demonstrate that painful stimuli are really blocked before reaching sensitive cortex, confirming our previous studies based on the absence of the cardiovascular reflex response. The reduced response to pain during hypnotic analgesia is therefore attributable to a reduced pain perception due to lack of activation of primary sensory cortex areas. It is interesting to note that the Brodmann areas 9 (frontal medial gyrus), 25 (anterior cingulate cortex) and 32 (cingulate gyrus), as well as the caudatum and the cerebellum were activated during hypnotic analgesia (Casiglia, Finatti, Tikhonoff et al., 2018), demonstrating that HFA must be considered as an active process: pain perception is prevented by the co-coordinated activity of different brain centers. This is object of a separate paper (Casiglia, Finatti et al., 2018).

\subsection{Hypnotic General Anaesthesia}

After years of experiments with HFA (corresponding to local anaesthesia), it became only natural for us to try to obtain hypnotic general anaesthesia (HGA). This was matter of uncertainty, as to our knowledge this possibility had never been explored before. General anaesthesia is a condition characterized by narcosis, complete analgesia, retrograde amnesia and in most cases surgical immobility (necessary for facilitating surgical maneuvers), and is usually preceded by pharmacological sedation.

In modern clinical practice, narcosis is usually obtained using intravenous barbiturates, analgesia with i.v. opioids, amnesia with i.v. benzodiazepines, and immobility with i.v. neuromuscular paralyzers (this requires ventilatory assistance, as the neuromuscular block is indiscriminate and acts on respiratory muscles too) (Figure 3, upper panel). These procedures are aimed at preventing pain, fear, anxiety, uncontrolled movement and unpleasant intervention reminder. In other cases, general anaesthesia without muscular paralysis (often called spontaneous-breathing anaesthesia or deep sedation) is obtained using a limited number of special drugs (Smith \& Goldman, 2018; Yentis, Hirsch, \& Smith, 1993). Our aim was to ascertain whether the same result could be obtained without any drugs, in the frame of hypnosis.

In an adequate number of highs, we decided to produce narcosis suggesting in hypnosis profound "hypnotic sleep", analgesia suggesting total-body HFA, and immobility suggesting flaccid paralysis (Casiglia et al., 2016). As specified above, we already had direct experience in all these fields taken separately. Amnesia is ${ }^{2}$ Of course, we know that hypnosis has nothing in common with sleep, but this is not relevant for the participant or-in a clinical view-for the patient, who has the experience of sleep. 


\section{PHARMACOLOGICAL GENERAL ANAESTHESIA}

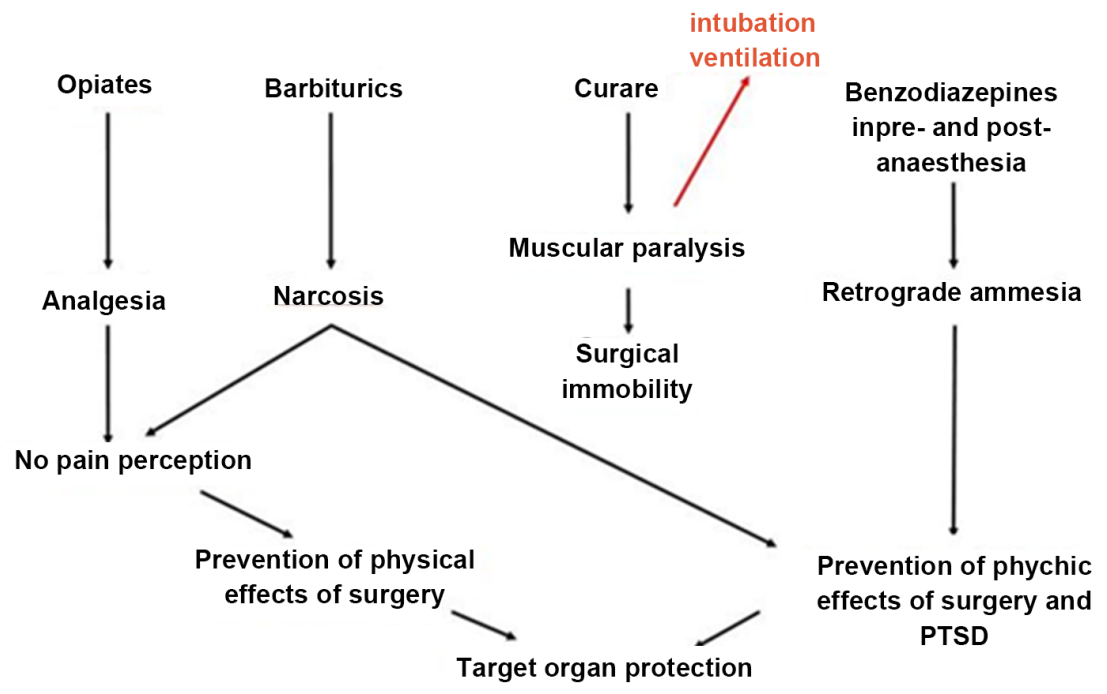

MODEL OF HYPNOTIC GENERAL ANAESTHESIA (HGA)

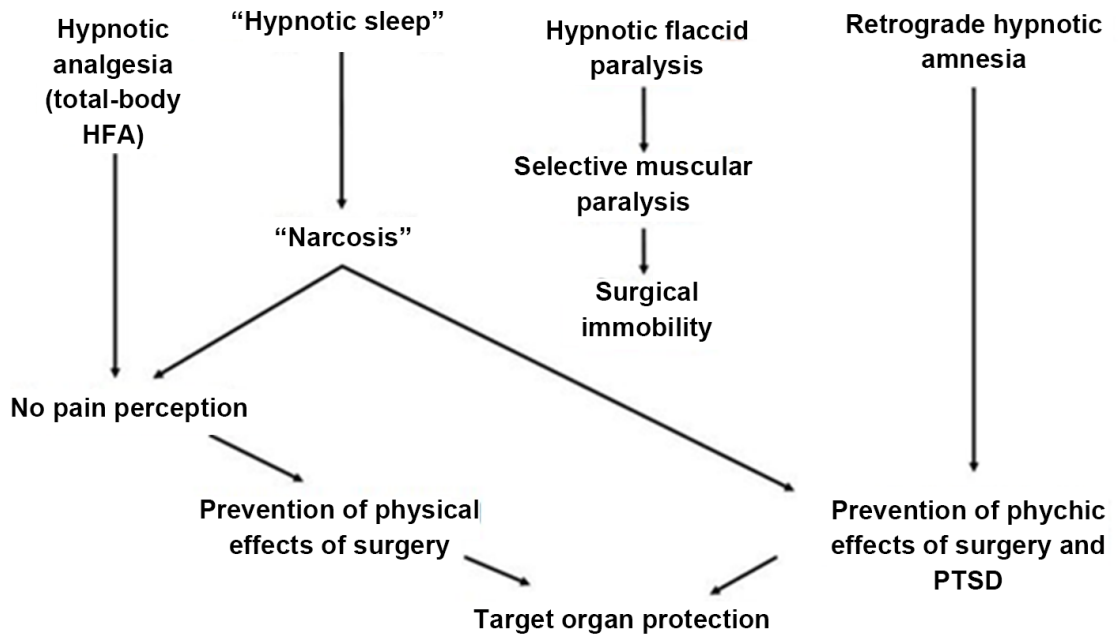

Figure 3. Flow charts showing the scheme of pharmacological general anaesthesia (upper panel) and of hypnotic general anaesthesia (lower panel).

very easy to obtain in deep hypnosis in highs (Frischholz, Lipman, Braun, \& Sachs, 2015), has been part of most of our previous experiments and has constantly been object of our lessons at the University of Padua and at the Institute Franco Granone of Turin. For these reasons, we were confident to be able to obtain the picture represented in Figure 3 (lower panel). As immobility was selective, respiratory muscles could be excluded from the block, making artificial ventilation unnecessary.

Electrical stimulation was chosen to induce pain (Casiglia et al., 1997); participants did not know in which part of the body the painful stimuli would have been produced time to time, so verifying, if any, a condition of general analgesia in the frame of HGA. 
As shown in Figure 4, complete analgesia to very intense electrical stimulation and block of reflex PR response was obtained in all participants, together with flaccid muscular paralysis (Casiglia \& Mentesana, 2018) without any need of artificial ventilation. The degree of analgesia obtained was even greater than that usually obtained by our research group with HFA. Not only this, but no participant had memory of what happened during the session, so documenting hypnotic amnesia. So, we demonstrated the possibility to obtain spontaneous-breathing HGA with nullification of pain and retrograde amnesia, exactly equivalent to spontaneous-breathing general anaesthesia or deep sedation (Casiglia et al., 1997).

HGA is fit, with the same procedure, for both general surgery and dentistry. A further advantage of this approach is that HGA is constantly preceded, accompanied and followed by deep sedation, making the surgical procedure more agréable. This is due to the intrinsic anxiolytic effect of neutral hypnosis and to specific suggestions of anxiolysis and well-being given to the participant. This is perfectly in agreement with the strategies to optimize analgesia and sedation (Schweickert \& Kress, 2008) and to reduce the use of opioids (Forget, 2018; Mauermann, Ruppen, \& Bandschapp, 2017) required by modern anaesthesia.

\subsection{Hypnotic Analgesia Obtained through Body Dysmorphism}

A novel way to obtain analgesia. HFA is generally produced giving suggestions of analgesia, such as: "Your hand is insensitive" or "Your hand doesn't feel

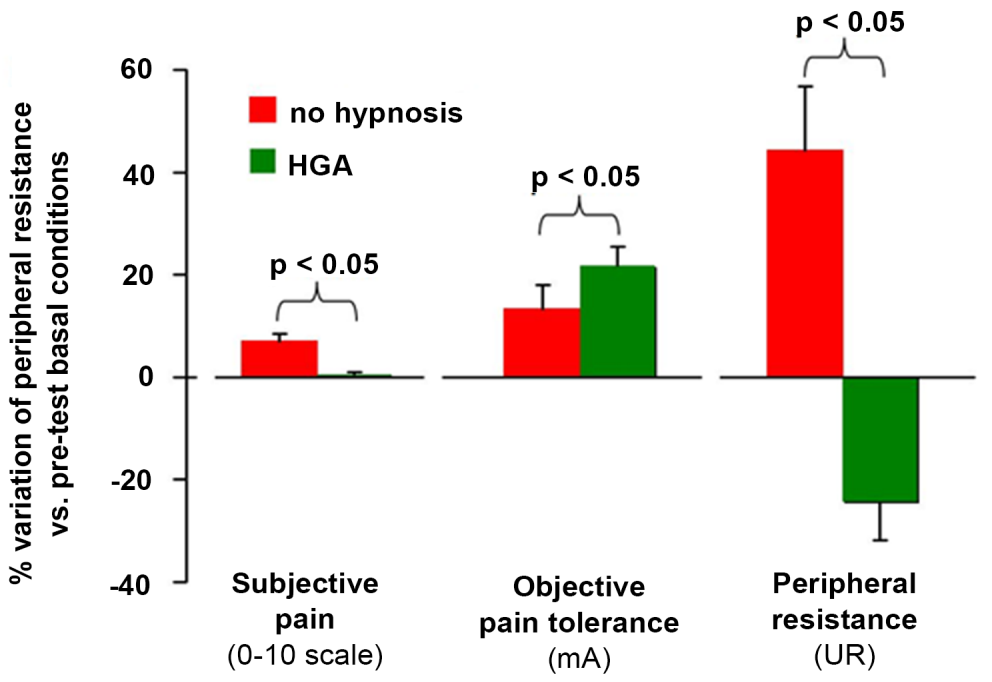

Figure 4. Percent variation from baseline of peripheral resistance (PR) during non-trigeminal pain tested out of hypnosis and in hypnotic general anaesthesia (HGA). In this latter condition, subjective perception of pain (measured in 0 to 10 scale) was significantly reduced, objective pain tolerance (measured in $\mathrm{mA}$ ) was significantly increased, and the expected physiological reflex PR increase in response to pain was non only significantly reduced, but also inverted like in pharmacological general anaesthesia, due to the anxiolytic effect of hypnosis. This demonstrates that painful stimuli are really blocked and not only dissociated, supporting the gate control. UR = units or resistance. 
the pain", in hypnotic trance. As shown above, in the modified consciousness that is typical of hypnosis, this suggestion (command) produces a physical effect.

In experimental setting (Casiglia et al., 2016), we examined for the first time the possibility of producing local anaesthesia by creating a hypnotic dysmorphism with a modification of body representation, without any direct suggestion of analgesia.

In practical terms, a hand was excluded from brain representation through the suggestion: "The left hand does not belong to your body".

In a number of participants adequate to this pilot study, each subject underwent a CPT painful stimulus in usual consciousness conditions and during hypnotic body dysmorphism of the left hand (in practical terms, it was suggested that the left hand, the wrist and the forearm up to the elbow no longer belonged to the body, as if they had been temporarily detached and placed upon an operating table where they would be subjected to the experiment). No direct suggestion of analgesia was given.

At the end of the experiment, the body representation was restored, while hemodynamic parameters continued to be registered until the eyes opening and complete dehypnotization.

Subjective pain and pain tolerance. Subjective perception of pain measured with an analogue scale during body dysmorphism with absence of the left hand was $92.5 \%$ lower at the first minute and $87.5 \%$ lower at maximal stimulation than it was during pre-hypnotic basal conditions. Pain perception was nullified in 5 out of 8 cases. Pain tolerance expressed as maximal voluntary duration of the immersion in icy water was $31.5 \%$ higher in dysmorphic conditions than in pre-hypnotic conditions.

Haemodynamic objectivation of pain. When the hypnotic dysmorphism was active, the systolic vasoconstriction observed in pre-hypnotic basal condition $(+4 \%$ at the first minute and $+14.8 \%$ at the end of the test) was nullified at the first minute (when $5 \%$ vasodilatation rather than vasoconstriction was even observed) and strongly reduced at the end of the test, thus showing a reduced pain-related stress. These results indicate that body dysmorphism is able to reduce per se not only subjective pain perception but also its adrenergic consequences. This is exactly what happens during real analgesia produced through chemical local anesthesia.

Role of dysmorphism. Dysmorphism-induced analgesia, being able not only to reduce and in most cases to nullify the subjective pain perception, but also to prevent its neurovegetative effects, is accompanied by (and probably due to) a real block of painful stimuli, like HFA, and is therefore comparable to that previously obtained through direct suggestion of analgesia (Chaves \& Dworkin, 1997; Facco et al., 2009). The exclusion of the hand from the body scheme was sufficient to produce a classic HFA, even though no specific suggestions of analgesia were given. 


\subsection{Remote Hypnotic Analgesia}

The possibility to obtain remote $H F A$, not in the presence of the hypnotist, was recently explored by our staff (Casiglia, Albertini et al., 2018).

Although hypnosis always depends on a strict relationship between the hypnotist and the participant, and the role of this rapport is not debatable, the ways and means of communication which can be used to create the hypnotist $\leftrightarrow$ subject relationship are not well defined. Is it always necessary to be face-to-face to create the rapport? The possibility of remote hypnotism with transmission of the hypnotic information by means of an electric or electronic device (for instance, by phone ${ }^{3}$ ) has been object of study since the XX Century (Cooperman \& Schafer, 1983; Gravitz, 1983; Owens, 1970; Roberts, 1978; Stanton, 1978; Van Nuys, 1977), but the studies in this field were mainly based on self-reports of efficacy and were not supported by objective and measurable data.

An indirect step forward in this field had been made by imaging studies ${ }^{4}$ in which hypnosis had to be managed via intercom and headphones (Demertzi et al., 2011; Douglas et al., 2014; McGeown et al., 2015; Müller, Batcha, Schrammb, \& Seitza, 2012; Raz, Fan, \& Posner, 2005), but the possibility of inducing hypnotic analgesia via these devices was never examined experimentally. We used a couple of transmitter-receiver (Figure 5) to put the participant into vocal contact with an expert hypnotist, who was located in a different room at many meters of distance.

Baseline CPT was preliminary performed with the usual operating methods. Then, to obtain HFA in the absence of the hypnotist (HFAR), radio hypnotic induction, deepening and body dysmorphism were obtained with verbal suggestions using the devices as communication means (Figure 5). The hypnotist and the participant were able to communicate throughout the test only using these devices. Suggestions of body dysmorphism were used to obtain HFA, and at the end of the test the restoration of body representation and the de-hypnotization were performed via two-way radio as well.

Subjective perception of pain was practically nullified by HFAR (Figure 6, left panel), while mean time of permanence in icy water, expressing the objective tolerance to pain, significantly by $194 \%$ with HFAR (Figure 6, intermediate panel).

Double product (systolic blood pressure heart rate, an alternative to $\mathrm{PR}$ as a marker of sympathetic drive) increased significantly during CPT $(+27.8 \%, \mathrm{p}<$ 0.01) out of hypnosis but not in HFAR (Figure 6, right panel).

The basis of the way to proceed described in this section was "belief" that the active and voluntary involvement of the subject and the relationship of confidence and trust between the hypnotist and the subjects would remain the ${ }^{3}$ In our experimental setting, we excluded the use of phone and used other devices to diversify from previous evidences, since hypnosis by phone has sometimes been used in stage hypnotism, a practice that we disapprove.

${ }^{4}$ See also the paragraphs "Neurological approach: role of imaging" and "Lessons from the neurological approach". 


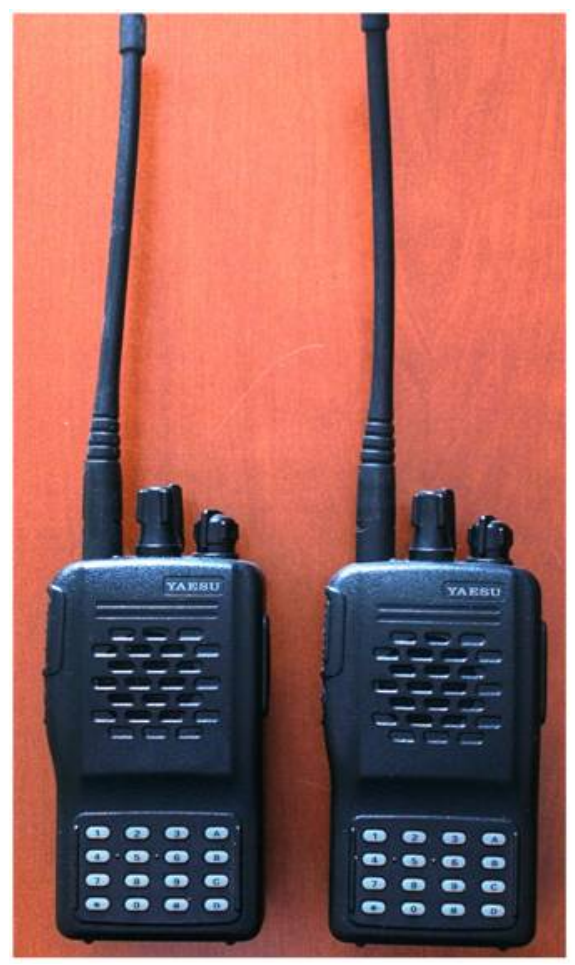

Figure 5. The couple of transmitter-receiver devices used to test remote hypnotic analgesia (Casiglia, Albertini et al., 2018).

no hypnosis

remote HFA
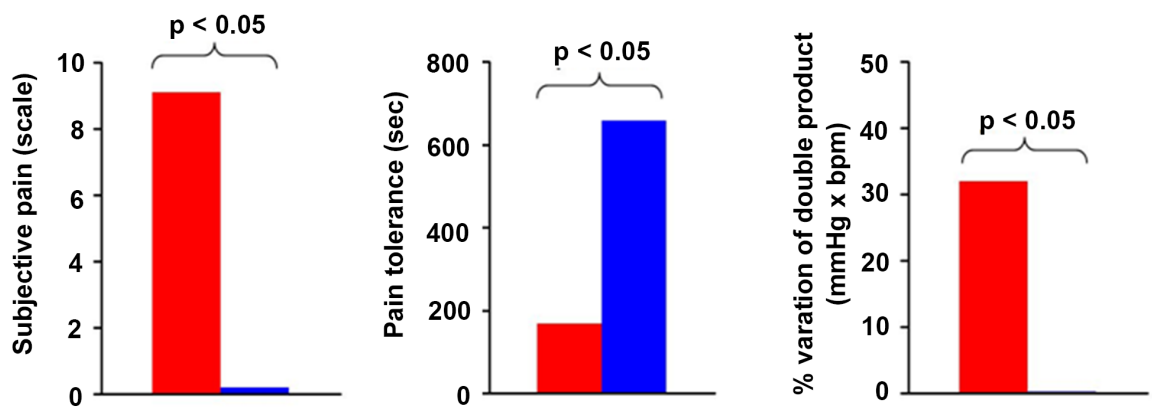

Figure 6. Subjective pain perception, objective pain tolerance (time of voluntary permanence in icy water) and variation vs. baseline of double product as reflex reaction to pain out of hypnosis and during remote hypnotic focused analgesia. Not only pain perception is significantly reduced, but pain tolerance is significantly increased and percent increase of double product is practically nullified, showing that painful stimuli are really blocked.

fundamental principles of hypnotic experience. What changed was only the way to obtain the hypnotist $\leftrightarrow$ participant rapport (Casiglia, 2012; Casiglia, Tikhonoff, \& Facco, 2016).

All participants reached both in the presence of the hypnotist and through radio-communication a comparable level of hypnosis: HFAR and HFAP were equivalent both in subjective pain perception and in objective pain conse- 
quences. Using a transceiver is therefore equal to being in front of the hypnotist: information can travel and reach its destination without being altered or lessened by the interposition of space or of a device between who sends and who receives it (Casiglia, Albertini et al., 2018), being the hypnotic message more important than the mean chosen to transmit it. This type of remote hypnotic analgesia obtained via a transceiver could be useful in emergency pain medicine, in disaster medicine or the management of situations in which subjects who can benefit from HFA cannot be reached directly or fast enough.

\section{Hypnotic Analgesia in Chronic Pain}

Our research group has essentially studied acute pain in a physiological setting using normal subjects as participants. Chronic pain is different from acute pain, and its treatment is different as well. In chronic pain, especially when related to severe or terminal illness (Facco, Casiglia, Zanette, \& Testoni, 2018), the emotional component is no less relevant than direct stimulation of nociceptors (Facco et al., 2013), since it inescapably leads to threat of disability and death being faced, with huge existential and philosophical issues related to the meaning of life and the perception of one's doom. Hypnosis can reduce both components of pain, but, just for this reason, chronic pain is more a psychotherapy-e.g., including strengthen of the Ego-than a simple medical treatment (Brugnoli et al., 2018). Different, synergistic methods must be employed to achieve an acceptable result. The target is not only the decrease of pain but also taking care of the suffering patient as a whole-i.e., improve anxiety and depression and other physical symptoms such as nausea and vomiting, allowing to optimize the long-term pharmacological treatment and help reducing the risk of adverse events. In this context, hypnosis for chronic pain is beyond the aims and scopes of this paper.

Chronic pain, the nature of which is subjective and not bi-univocally tied to pain pathways, is a very complex topic and its pharmacological management is often below the expectations of both patients and physicians. The conventional approach-based on the ruling materialist-reductionist view of medical science and focused on organic aspects and their pharmacological or interventional manipulation-is far from being enough and may also lead to misdiagnosis and wrong treatments; furthermore, it is self-contradictory, since it does not meet the universally accepted definition of pain in medicine. The International Association for the Study of Pain has wisely defined pain as a psychosomatic experience involving sensory and emotional experience, associated with actual or potential tissue damage, or described in terms of such damage (Merskey, 1994, 2007). This definition avoids tying pain to nociceptive pathways only and clearly shows that its nature is essentially a matter of experience: without experience there is no pain. On the other hand, the experience of disease, pain and received treatments influence each other and are deeply affected by psychological, social and cultural factors, where pain intensity, despite essential, is far from being the 
only target of assessment (Facco, Testoni, Di Lucia, Ronconi, \& Drusini, 2013). Thus, its management must move beyond the mere use of drugs and invasive procedures.

The above-mentioned factors explain why chronic pain therapy remains in many cases elusive and there is no clear, shared agreement on how managing it effectively: as emphasized by Loeser (2005), pain management is a chaotic component, confusing patients, health care providers, and payers. Its management would benefit from a holistic approach, taking into account patient's subjectivity in order to improve the patient-doctor relationship and the capacity of properly understanding the patient (Cepeda et al., 2008; Charon, 2012). In short, Voltaire's aphorism "Doctors pour drugs, of which they know little, for diseases of which they know less, into patients of whom they know nothing" remains a topical statement in the field of pain.

As discussed above, hypnosis is a tremendous tool, able to strongly improve one's control over both mind and body. In chronic pain it may help the patient to change pain perception and restructure his/her problem, altering perception, and other related physical symptoms as well as the impact of diagnosis and emotional components. In this regard, it is worth noting that the nocebo effect, springing from a bad doctor-patient relationship and communication, may yield hyperalgesia and allodynia, decreased quality of life, lower the adherence to therapy, and increase anxiety (Benedetti, Lanotte, Lopiano, \& Colloca, 2007; Brody, Colloca, \& Miller, 2012; Colloca, Sigaudo, \& Benedetti, 2008; Petersen et al., 2014). Therefore, patient's management with an unyielding mechanistic-reductionist approach only focused on the disease and oblivious of the patient's subjectivity is a relevant cause of avoidable pain and suffering.

Given the above-mentioned factors, the management of chronic pain is a much more complex topic than acute and procedural pain, since it is far from being a simple symptom of disease; rather, it involves the suffering of the whole human being, confronting him/her with the limits of existence and its doom, the threat of disease, disability and death. In other words, a chronic, refractory pain raises the huge, unsolved philosophical problem of humanity of all ages, a matter for philosophy and resilience, cognition and metacognition. Here, the pharmacological manipulation is only one small step in a much wider management; it also calls for a hypnotic management taking into account all its physical, psychological and existential components, besides hypnotic suggestion aimed to increase pain threshold (Facco, Casiglia, Zanette, \& Testoni, 2018). The appropriate approach must be tailored taking into account patient's diagnosis and his/her view of the whole of pain, symptoms, suffering and their perceived meaning, where hypnosis-besides pain relief_-may be usefully aimed to Ego strengthening, resilience, downsizing of feared outcome, acceptance and emotional stability.

\section{Final Considerations about the Meaning and the Nature of Hypnotic Analgesia and Anaesthesia}

It has been repeatedly suggested that hypnotic analgesia is due to dissociation, a 
hypothesis that seems to be the essence of the belief of many psychologists. On the contrary, in the light of our results, the so-called neodissociation model (Croft, Williams, Haenschel, \& Gruzelier, 2002; Gruzelier, 1998) must be rejected $^{5}$. The sociocognitive theory (in which hypnotic analgesia is attributed to a sort of distraction of attention) (Chapman \& Nakamura, 1998; Spanos, Kennedy, \& Gwynn, 1984; Spanos, Radke-Bodoric, \& Ferguson, 1979) must be rejected as well. In fact, in such model too no reduction of cardiovascular pain reflexes could be observed. For the same reason, we must reject the constructivistic theory as an explanation of hypnotic analgesia. Followers of this theory believe that, since consciousness has limited capacities, only a single scheme of reality (i.e. one that excludes consciousness of pain) can occupy it in every moment. In this case as well, however, differently from what we observed in our experience, the cardiovascular reflex response to pain should be fully kept during pain. The experiments conducted in our Laboratory with specific suggestions of analgesia (Casiglia et al., 2007) or with suggestion of body dysmorphism (Casiglia et al., 2016), with the rapport hypnotist $\leftrightarrow$ participant obtained having both in the same room or in remote (Casiglia, Albertini et al., 2018), using brain imaging (Casiglia et al., 2010; Casiglia, Finatti, Tikhonoff et al., 2018; Casiglia, Tikhonoff, Giordano, Regaldo, Facco et al., 2012; Priftis et al., 2011) or cardiovascular reflexes (Casiglia et al., 2007, 2015, 2016; Facco et al., 2009, 2013, 2018; Facco, Casiglia, Masiero et al., 2011; Facco, Casiglia, Zanette et al., 2011; Facco, Zanette et al., 2014), using PR increase during NTP or PR decrease during TP (Casiglia et al., 2007, 2015, 2016; Facco et al., 2013; Facco, Casiglia, Zanette et al., 2011), limiting analgesia to HFA or extending it to HGA (Casiglia et al., 2007, 2015), tips the scale in favor of a real antalgic block rather than of a dissociation. In fact, not only brain sensorial areas are silent when pain is inhibited by hypnotic analgesia, but the reflex sympathetic reaction to pain is inhibited as well.

This demonstrates that 1) hypnosis exists, 2) hypnotic analgesia exists, 3) painful stimuli are blocked at a certain level of the nervous system, a level that actually has probably been detected (Melzack \& Wall, 1965; Ossipov et al., 2010). Our experiments therefore come out in favor of the gate-control theory (Kiernan, Dane, Phillips, \& Price, 1995; Sandrini et al., 2000). Selective cognitive processes transmitted by descending fibers might modulate the properties of the spinal cord giving concreteness to the gating. Modifications of the spinal nociceptive reflexes $\mathrm{R}_{\mathrm{III}}$ have actually been registered during hypnosis (Hilgard, 1977). Of course, it is also possible that hypnosis works on multiple levels, being pain a multidimensional experience involving "not only sensorial but also dissociative, motivational, cognitive and emotional factors" (Casiglia et al., 2016). Hypnotic suggestions could therefore work by modulating not only $\mathrm{R}_{\mathrm{III}}$ in the ${ }^{5}$ According to such theories, pain is still registered in conditions of hypnotic anesthesia, but remains dissociated from the critical and emotional consciousness, being masked by an amnesic barrier (Becker \& Yingling, 1998; Crawford, 1990; Hilgard, 1977; Hilgard, 1979; Holroyd, 1996; Pribram, 1991); it is true that a certain level of dissociation is present in hypnosis (even when neutral) but, if this was the only mechanism implied in hypnotic analgesia, a normal cardiovascular reflex response should be registered. 
spinal cord but also the sensation of pain above and beyond $\mathrm{R}_{\mathrm{III}}$ (Kiernan et al., 1995). The down-regulation of pain and of its effects corroborates the hypothesis of a reduction of polysynaptic spinal reflexes, and a cortical reshaping of the affective and perceptive dimension of pain. Finally, conscious and unconscious control processes are certainly associated to a supervision system of attentive nature involving the frontotemporal cortex and the limbic system.

We hope the present paper is able to help improve knowledge about hypnotic analgesia, making it less mysterious and more pertinent to human physiology. Research in this field must continue, also taking into consideration larger number of participants, eventually different from highs, and the so-called echo-genetic context (Stolarz, Staessen, Kawecka-Jaszcs, Brand, Bianchi, Kouznetsova et al., 2004; Tikhonoff, Kuznetsova, Stolarz, Bianchi, Casiglia, Kawecka-Jaszcz et al., 2003) that is acting as a confounder in a number of experimental settings.

\section{References}

Becker, D. E., \& Yingling, C. D. (1998). Intracranial Recording during Hypnotic Analgesia. International Journal of Psychophysiology, 28, 317-318. https://www.sciencedirect.com/science/article/abs/pii/S0167876097000767

Benedetti, F., Lanotte, M., Lopiano, L., \& Colloca, L. (2007). When Words Are Painful: Unraveling the Mechanisms of the Nocebo Effect. Neuroscience, 147, 260-271. https://doi.org/10.1016/j.neuroscience.2007.02.020

Brody, H., Colloca, L., \& Miller, F. G. (2012). The Placebo Phenomenon: Implications for the Ethics of Shared Decision-Making. Journal of General Internal Medicine, 27, 739-742. https://doi.org/10.1007/s11606-011-1977-1

Brugnoli, M. P., Pesce, G., Pasin, E., Basile, M. F, Tamburin, D., \& Polati, E. (2018). The Role of Clinical Hypnosis and Self-Hypnosis to Relief Pain and Anxiety in Severe Chronic Diseases in Palliative Care: A 2-Year Long-Term Follow-Up of Treatment in a Nonrandomized Clinical Trial. Annals of Palliative Medicine, 7, 17-31. https://doi.org/10.21037/apm.2017.10.03

Casiglia, E. (2008). Hypnosis in the Theory of the Bicameral Mind. Jaynesian, 2, 12-14.

Casiglia, E. (2012). Why Is It So Easy to Hypnotize? An Editorial Commentary about the Recent Article by M. Kuijsten. Contemporary Hypnosis \& Integrative Therapy, 29, 309-314.

Casiglia, E. (2015). Trattato d'ipnosi e altre modificazioni di coscienza. Padova, IT: CLEUP.

Casiglia, E., \& Mentesana, L. (2018). Instrumental Demonstration of Hypnotic Flaccid Paralysis of Corrugator Muscles and Its Use in Esthetic Medicine. Sleep and Hypnosis, 20, 60-66. http://www.sleepandhypnosis.org/ing/abstract.aspx?MkID=236

Casiglia, E., Albertini, F., Tikhonoff, V., Gasparotti, F., Favaro, J., Finatti, F. et al. (2018). Experimental Approach to the Transmission of Information in Hypnosis. Psychology, 9, 1-13. https://doi.org/10.4236/psych.2018.91001

Casiglia, E., Finatti, F., Gasparotti, F., Stabile, M. R., Mitolo, M., Albertini, F. et al. (2018). Functional Magnetic Resonance Imaging Demonstrates That Hypnosis Is Conscious and Voluntary. Psychology, 9, 1571-1581. https://doi.org/10.4236/psych.2018.97095

Casiglia, E., Finatti, F., Tikhonoff, V., Stabile, M. R., Mitolo, M., Albertini, F. et al. (2018). Mechanisms of Hypnotic Analgesia Explained by Functional Magnetic Resonance Imaging. Brain Imaging and Behavior, in Press. 
Casiglia, E., Mazza, A., Ginocchio, G., Onesto, C., Pessina, A. C., Rossi, A. et al. (1997). Haemodynamics Following Real and Hypnosis-Simulated Phlebotomy. American Journal of Clinical Hypnosis, 40, 368-375. https://doi.org/10.1080/00029157.1997.10403405

Casiglia, E., Rempelou, P., Tikhonoff, V., Giacomello, M., Finatti, F., Albertini, F. et al. (2016). Hypnotic Focused Analgesia Obtained through Body Dysmorphism Prevents Both Pain and Its Cardiovascular Effects. Sleep and Hypnosis, 19, 89-95. http://www.sleepandhypnosis.org/ing/abstract.aspx?MkID=224

Casiglia, E., Rempelou, P., Tikhonoff, V., Guidotti, F., Giacomello, M., Lapenta, A. M., \& Facco, E. (2015). Hypnotic General Anesthesia vs. Focused Analgesia in Preventing Pain and Its Cardiovascular Effects. ATINER's Conference Paper Series, INM2015-1638.

Casiglia, E., Rossi, A., Mazza, A., Cavattoni, G., Colangeli, G., Ginocchio, G. et al. (1994). Hypnosis as a Tool for Evaluating the Cortical Component of Haemodynamic Variations. Pilot Study during Blood Letting. High Blood Pressure, 3, 8.

Casiglia, E., Rossi, A., Tikhonoff, V., Scarpa, R., Tibaldeschi, G., Giacomello, M. et al. (2006). Local and Systemic Vasodilation Following Hypnotic Suggestion of Warm Tub Bathing. International Journal of Psychophysiology, 62, 60-65.

https://doi.org/10.1016/j.ijpsycho.2006.01.012

Casiglia, E., Schiavon, L., Tikhonoff, V., Haxhi Nasto, H., Azzi, M., Rempelou, P. et al. (2007). Hypnosis Prevents the Cardiovascular Response to Cold Pressor Test. American Journal of Clinical Hypnosis, 49, 255-266. https://doi.org/10.1080/00029157.2007.10524503

Casiglia, E., Schiff, S., Tikhonoff, V., Schiavon, L., Bascelli, A., Haxhi Nasto, H. et al. (2010). Neurophysiological Correlates of Post-Hypnotic Alexia. A Controlled Study with Stroop Test. American Journal of Clinical Hypnosis, 52, 219-234. https://doi.org/10.1080/00029157.2010.10401721

Casiglia, E., Tikhonoff, V., \& Facco, E. (2016). The Unconscious Experimentally Demonstrated by Means of Hypnosis. Psychology, 7, 469-479. https://doi.org/10.4236/psych.2016.74048

Casiglia, E., Tikhonoff, V., Giordano, N., Regaldo, G., Facco, E., Marchetti, P. et al. (2012). Relaxation versus Fractionation as Hypnotic Deepening: Do They Differ in Physiological Changes? International Journal of Clinical and Experimental Hypnosis, 60, 338-355. https://doi.org/10.1080/00207144.2012.675297

Casiglia, E., Tikhonoff, V., Giordano, N., Regaldo, G., Tosello, M. T., Rossi, A. M. et al. (2012). Measured Outcomes with Hypnosis as an Experimental Tool in a Cardiovascular Physiology Laboratory. International Journal of Clinical and Experimental Hypnosis, 60, 241-261. https://doi.org/10.1080/00207144.2012.648078

Cepeda, M. S., Chapman, C. R., Miranda, N., Sanchez, R., Rodriguez, C. H., Restrepo, A. E. et al. (2008). Emotional Disclosure through Patient Narrative May Improve Pain and Well-Being: Results of a Randomized Controlled Trial in Patients with Cancer Pain. Journal of Pain and Symptom Management, 35, 623-631. https://doi.org/10.1016/j.jpainsymman.2007.08.011

Chapman, R. C., \& Nakamura, Y. (1998). Hypnotic Analgesia: A Constructivist Framework. International Journal of Clinical and Experimental Hypnosis, 46, 6-27. https://doi.org/10.1080/00207149808409987

Charon, R. (2012). At the Membranes of Care: Stories in Narrative Medicine. Academic Medicine, 87, 342-347. https://doi.org/10.1097/ACM.0b013e3182446fbb

Chaves, J. F., \& Dworkin, S. F. (1997). Hypnotic Control of Pain: Historical Perspectives and Future Prospects. International Journal of Clinical and Experimental Hypnosis, 45, 
356-376. https://doi.org/10.1080/00207149708416138

Colloca, L., Sigaudo, M., \& Benedetti, F. (2008). The Role of Learning in Nocebo and Placebo Effects. Pain, 136, 211-218. https://doi.org/10.1016/j.pain.2008.02.006

Cooperman, S., \& Schafer, D. W. (1983). Hypnotherapy over the Telephone. American Journal of Clinical Hypnosis, 25, 277-279. https://doi.org/10.1080/00029157.1983.10404115

Crawford, H. J. (1990). Cognitive and Psychophysiological Correlates of Hypnotic Responsiveness and Hypnosis. In M. L. Fass, \& Brown, D. (Eds.), Creative Mastery in Hypnosis and Hypnoanalysis: A Festschrift for Erika Fromm (pp. 47-54). Hillsdale, NJ: Erlbaum.

Croft, R. J., Williams, J. D., Haenschel, C, \& Gruzelier, J. H. (2002). Pain Perception, Hypnosis and $40 \mathrm{~Hz}$ Oscillations. International Journal of Psychophysiology, 46, 101-108. https://doi.org/10.1016/S0167-8760(02)00118-6

De Pascalis, V., Russo, O., \& Marrucci, F.S. (2000). Italian Norms for the Harvard Group Scale of Hypnotic Susceptibility, Form A. International Journal of Clinical and Experimental Hypnosis, 48, 44-55. https://doi.org/10.1080/00207140008410360

Demertzi, A., Soddu, A., Faymonville, M. E., Bahri, M. A., Gosseries, O., Vanhaudenhuyse, A. et al. (2011). Hypnotic Modulation of Resting State fMRI Default Mode and Extrinsic Network Connectivity. In E. J. W. Van Someren, Y. D. Van Der Werf, P. R. Roelfsema, H. D. Mansvelder, \& F. H. L. Da Silva (Eds.), Slow Brain Oscillations of Sleep, Resting State and Vigilance (Progress in Brain Research) (Vol. 193, pp. 309-322). Amsterdam: Elsevier. https://doi.org/10.1016/B978-0-444-53839-0.00020-X

Douglas, P. K., Pisani, M., Reid, R., Head, A., Lau, E., Mirakhor E. et al. (2014). Method for Simultaneous fMRI/EEG Data Collection during a Focused Attention Suggestion for Differential Thermal Sensation. Journal of Visualized Experiments, No. 83, e3298. https://doi.org/10.3791/3298

Facco, E., Casiglia, E., Masiero, S., Tikhonoff, V., Giacomello, M., \& Zanette, G. (2011). Effects of Hypnotic Focused Analgesia on Dental Pain Threshold. International Journal of Clinical and Experimental Hypnosis, 59, 454-468.

https://doi.org/10.1080/00207144.2011.594749

Facco, E., Casiglia, E., Zanette, G., \& Testoni, I. (2018). On the Way of Liberation from Suffering and Pain: Role of Hypnosis in Palliative Care. Annals of Palliative Medicine, 7, 63-74. https://doi.org/10.21037/apm.2017.04.07

Facco, E., Casiglia, E., Zanette, G., Bacci, C., Cavallin, F., \& Manani, G. (2011). The Effects of Hypnosis on Dental Pain Threshold. International Journal of Oral \& Maxillofacial Surgery, 40, 1058-1059. https://doi.org/10.1016/j.ijom.2011.07.112

Facco, E., Casiglia, E., Zanette, G., Masiero, S., Bacci, C., Lapenta, A. M., \& Manani, G. (2009). Effects of Hypnosis on Dental Pain Threshold. Preliminary Report. Pain Practice, 9, 47-48.

Facco, E., Ermani, M., Rampazzo, P., Tikhonoff, V., Saladini, M., Zanette, G. et al. (2014). Top-Down Regulation of Left Temporal Cortex by "Hypnotic Amusia for Rhythm": A Pilot Study on Mismatch Negativity. International Journal of Clinical and Experimental Hypnosis, 62, 129-144. https://doi.org/10.1080/00207144.2014.869124

Facco, E., Pasquali, S., Zanette, G., \& Casiglia, E. (2013). Hypnosis as Sole Anaesthesia for Skin Tumour Removal in a Patient with Multiple Chemical Sensitivity. Anaesthesia, 68, 961-965. https://doi.org/10.1111/anae.12251

Facco, E., Testoni, I., Di Lucia, D., Ronconi, L., \& Drusini, A. (2013). Relevance of a Biocultural Approach in the Assessment of Chronic Pain: A Comparison between Peruvian Women Living in Nasca and Lima. World Cultural Psychiatry Research Review, 8 , 
60-70.

Facco, E., Testoni, I., Ronconi, L., Casiglia, E., Zanette, G., \& Spiegel, D. (2017). Psychological Features of Hypnotizability: A First Step towards Its Empirical Definition. International Journal of Clinical and Experimental Hypnosis, 65, 98-119. https://doi.org/10.1080/00207144.2017.1246881

Facco, E., Zanette, G., \& Casiglia, E. (2014). The Role of Hypnosis in Dentistry. SAAD Digest, 30, 3-6.

Forget, P. (2018). Opioid-Free Anaesthesia. Why and How? A Contextual Analysis. Anaesthesia, Critical Care \& Pain Medicine, pii: S2352-5568(18)30017-1. https://europepmc.org/abstract/med/29775728

Freeman, R., Barabasz, A., Barabasz, M., \& Warner, D. (2000). Hypnosis and Distraction Differ in Their Effects on Cold Pressor Pain. American Journal of Clinical Hypnosis, 43, 137-148. https://doi.org/10.1080/00029157.2000.10404266

Frischholz, E. J., Lipman, L. S., Braun, B. G., \& Sachs, R. (2015). Suggested Posthypnotic Amnesia in Psychiatric Patients and Normals. American Journal of Clinical Hypnosis, 57, 110-121. https://doi.org/10.1080/00029157.2015.967059

Giordano, N., Tikhonoff, V., Tosello, M. T., Lapenta, A. M., \& Casiglia, E. (2012). An Experimental Approach to Hypnotic Age Regression: Controlled Study over 10 Healthy Participants. Contemporary Hypnosis \& Integrative Therapy, 29, 271-283.

Gravitz, M. A. (1983). Early Use of the Telephone and Recordings in Hypnosis. American Journal of Clinical Hypnosis, 25, 280-282. https://doi.org/10.1080/00029157.1983.10404116

Gruzelier, J. H. (1998). A Working Model of the Neurophisiology of Hypnosis: A Review of Evidence. Contemporary Hypnosis, 15, 3-21. https://doi.org/10.1002/ch.112

Hilgard, E. R. (1977). Divided Consciousness: Multiple Controls in Human Thought and Action. New York, NY: Wiley.

Hilgard, E. R. (1979). Personality and Hypnosis: A Study of Immaginative Involvement. Chicago, IL: University of Chicago Press.

Holroyd, J. (1996). Hypnosis Treatment of Clinical Pain: Understanding Why Hypnosis Is Useful. International Journal of Clinical and Experimental Hypnosis, 44, 33-51. https://doi.org/10.1080/00207149608416066

Horton, J., Crawford, H., Harrington, G., \& Downs, H. (2004). Increased Anterior Corpus Callosum Size Associated Positively with Hypnotisability and the Ability to Control Pain. Brain, 127, 1741-1747. https://doi.org/10.1093/brain/awh196

Ibrahim, M. M. (1975). Localization of Lesion in Patients with Idiopathic Orthostatic Hypotension. Heart, 37, 868-872. https://doi.org/10.1136/hrt.37.8.868

Kiernan, B. D., Dane, J. R., Phillips, L. H., \& Price, D. D. (1995). Hypnotic Analgesia Reduces R-III Nociceptive Reflex: Further Evidence Concerning the Multifactorial Nature of Hypnotic Analgesia. Pain, 60, 39-47. https://doi.org/10.1016/0304-3959(94)00134-Z

Loeser, J. D. (2005). Pain: Disease or Dis-Ease? The John Bonica Lecture: Presented at the Third World Congress of World Institute of Pain, Barcelona 2004. Pain Practice, 5, 77-84. https://doi.org/10.1111/j.1533-2500.2005.05204.x

Mauermann, E., Ruppen, W., \& Bandschapp, O. (2017). Different Protocols Used Today to Achieve Total Opioid-Free General Anesthesia without Locoregional Blocks. Best Practice \& Research Clinical Anaesthesiology, 31, 533-545. https://doi.org/10.1016/j.bpa.2017.11.003

McGeown, W. J., Mazzoni, G., Vannucci, M., \& Venneri, A. (2015). Structural and Functional Correlates of Hypnotic Depth and Suggestibility. Psychiatry Research, 231, 
151-159. https://doi.org/10.1016/j.pscychresns.2014.11.015

McGeown, W. J., Mazzoni, G., Venneri, A., \& Kirsch, I. (2009). Hypnotic Induction Decreases Anterior Default Mode Activity. Consciousness and Cognition, 18, 848-855. https://doi.org/10.1016/j.concog.2009.09.001

Melzack, R., \& Wall, P. D. (1965). Pain Mechanisms: A New Theory. Science, 150, 971-979. https://doi.org/10.1126/science.150.3699.971

Merskey, H. (1994). Logic, Truth and Language in Concepts of Pain. Quality of Life Research, 3, S69-S76. https://doi.org/10.1007/BF00433379

Merskey, H. (2007). The Taxonomy of Pain. Medical Clinics of North America, 91, 13-20. https://doi.org/10.1016/j.mcna.2006.10.009

Mitchell, L. A., MacDonald, R. A. R., \& Brodie, E. E. (2004). Temperature and the Cold Pressor Test. Journal of Pain, 5, 233-237. https://doi.org/10.1016/j.jpain.2004.03.004

Müller, K., Bachta, K., Schrammb, S., \& Seitza, R. J. (2012). The Facilitating Effect of Clinical Hypnosis on Motor Imagery: An fMRI Study. Behavioural Brain Research, 231, 164-169. https://doi.org/10.1016/j.bbr.2012.03.013

Ossipov, M. H., Dussor, G. O., \& Porreca, F. (2010). Central Modulation of Pain. Journal of Clinical Investigation, 120, 3779-3787. https://doi.org/10.1172/JCI43766

Owens, H. E. (1970). Hypnosis by Phone. American Journal of Clinical Hypnosis, 13, 57-60. https://doi.org/10.1080/00029157.1970.10402078

Peckerman, A., Hurwitz, B. E., Saab, P. G., Llabre, M. M., MacCabe, P. M., \& Schneiderman, N. (1994). Stimulus Dimension of the Cold Pressor Test and the Associated Patterns of Cardiovascular Response. Psychophysiology, 31, 282-290.

https://doi.org/10.1111/j.1469-8986.1994.tb02217.x

Peckerman, A., Saab, P. G., Llabre, M. M., Hurwitz, B. E., McCabe, P. M., \& Schneiderman, N. (1998). Cardiovascular and Perceptual Effects of Reporting Pain during the Foot and Forehead Cold Pressor Tests. International Journal of Behavioral Medicine, 5, 106-117. https://doi.org/10.1207/s15327558ijbm0502_2

Peckerman, A., Saab, P. G., McCabe, P. M., Skyler, J. S., Winters R. W., Llabre, M. M., \& Schneiderman, N. (1991). Blood Pressure Reactivity and Perception of Pain during the Forehead Cold Pressor Test. Psychophysiology, 28, 485-495.

https://doi.org/10.1111/j.1469-8986.1991.tb01985.x

Petersen, G. L., Finnerup, N. B., Colloca, L., Amanzio, M., Price, D. D., Jensen, T. S., \& Vase, L. (2014). The Magnitude of Nocebo Effects in Pain: A Meta-Analysis. Pain, 155, 1426-1434. https://doi.org/10.1016/j.pain.2014.04.016

Pribram, K. H. (1991). Brain and Perception: Holonomy and Structure in Figural Processing. New York, NY: Hillsdale.

Priftis, K., Schiff, S., Tikhonoff, V., Giordano, N., Amodio, P., Umiltà, C., \& Casiglia, E. (2011). Hypnosis Meets Neurosciences: Simulating Visuospatial Neglect in Healthy Participants. Nuropsychologia, 49, 3346-3350.

https://doi.org/10.1016/j.neuropsychologia.2011.08.008

Raz, A., Fan, J., \& Posner, M. I. (2005). Hypnotic Suggestion Reduces Conflict in the Human Brain. Proceedings of the National Academy of Sciences of the United States of America, 102, 9978-9983. https://doi.org/10.1073/pnas.0503064102

Roberts, J. A. (1978). Hypnosis by Telephone. Medical Journal of Australia, 2, 158-160.

Sandrini, G., Milanov, I., Malaguti, S., Nigrelli, M. P., Moglia, A., \& Nappi, G. (2000). Effects of Hypnosis on Diffuse Noxius Inhibitory Controls. Physiology \& Behaviour, 69, 295-300. https://doi.org/10.1016/S0031-9384(00)00210-9

Schweickert, W. D., \& Kress, J. P. (2008). Strategies to Optimize Analgesia and Sedation. 
Critical Care, 12, S6. https://doi.org/10.1186/cc6151

Sevre, K., \& Rostrup, M. (1999). Blood Pressure and Heart Rate Responses to Cold Pressor Test in Patients Admitted to Hospital Due to Chest Pain. Blood Pressure, 8, 110-113. https://doi.org/10.1080/080370599438284

Sharav, Y., \& Tal, M. (2006). Focused Hypnotic Analgesia: Local and Remote Effects. Pain, 124, 280-286. https://doi.org/10.1016/j.pain.2006.04.016

Smith, G., \& Goldman, J. (2018). General Anesthesia for Surgeons. Treasure Island, FL: StatPearls Publishing.

Spanos, N. P., Kennedy, S. K., \& Gwynn, M. I. (1984). Moderating Effects of Contextual Variables on the Relationship between Hypnotic Susceptibility and Suggested Analgesia. Journal of Abnormal Psychology, 93, 285-294.

https://doi.org/10.1037/0021-843X.93.3.285

Spanos, N. P., Radke-Bodoric, H. L., \& Ferguson, J. D. (1979). The Effects of Hypnotic Susceptibility, Suggestions for Analgesia, and the Utilization of Cognitive Strategies on the Reduction of Pain. Journal of Abnormal Psychology, 88, 282-292.

https://doi.org/10.1037/0021-843X.88.3.282

Stanton, H. E. (1978). Hypnotherapy at a Distance through Use of the Telephone. American Journal of Clinical Hypnosis, 20, 278-281. https://doi.org/10.1080/00029157.1978.10403945

Stolarz, K., Staessen, J. A., Kawecka-Jascs, K., Brand, E., Bianhi, G., Kuznetsova, T. et al. (2004). Genetic Variation in $C Y P 11 B 2$ and $A T 1 R$ Influences Heart Rate Variability Conditional on Sodium Excretion. Hypertension, 44, 156-162.

https://doi.org/10.1161/01.HYP.0000135846.91124.a5

Tikhonoff, V., Azzi, D., Boschetti, G., Giordano, N., Rempelou, P., Giacomello, M. et al. (2012). Increase of Isometric Performance via Hypnotic Suggestion: Experimental Study over 10 Young Healthy Volunteers. Contemporary Hypnosis \& Integrative Therapy, 29, 352-362.

Tikhonoff, V., Kuznetsova, T., Stolarz, L., Bianchi, H., Casiglia, E., Kawecka-Jascs, K. et al. (2003). Beta-Adducin Polymorphism, Blood Pressure, and Sodium Excretion in Three European Populations. American Journal of Hypertension, 16, 840-846. https://doi.org/10.1016/S0895-7061(03)00975-0

Tikhonoff, V., Senzolo, M., Lapenta, A. M., Palatini, P., \& Casiglia, E. (2018). Hypnotic Hallucination of Body Heating Modifies Splanchnic Circulation: Haemodynamic and Ultrasonographic Pilot Study in Normal Volunteers. Sleep and Hypnosis, 20, 31-39. http://www.sleepandhypnosis.org/ing/abstract.aspx?MkID=233

Van Nuys, D. (1977). Successful Treatment of Sacroiliac Pain by Telephone. A Brief Clinical Report. Journal of the American Society of Psychosomatic Dentistry and Medicine, 24, 73-75.

Yentis, S. M., Hirsch, N. P., \& Smith, G. B. (1993). Anaesthesia A to Z. Oxford, UK: Butterworth-Heinemann.

Younger, J. (2005). The Harvard Group Scale of Hypnotic Susceptibility: Accuracy of Self-Report and the Memory for Items. International Journal of Clinical and Experimental Hypnosis, 53, 306-320. https://doi.org/10.1080/00207140590961411 